\title{
Conceptualising English as a lingua franca (ELF) as a tertiary classroom language
}

\author{
Ute Smit \\ Department of English Studies, University of Vienna, Spitalgasse 2, Hof 8. 1090 Vienna, Austria \\ Email: ute.smit@univie.ac.at
}

\begin{abstract}
This contribution draws on the notion of English as a lingua franca, especially as discussed in James (2006) and Smit (2010), to conceptualise English-medium tertiary education in settings where English functions as additional language and where tertiary education has a history of being undertaken in other, usually national languages. After briefly sketching the recent research undertakings into English as a lingua franca (ELF) as well as the specificities of English-medium tertiary education in mainland Europe, the paper argues for a conceptual framework of ELF as classroom language that combines sociolinguistic, sociocultural and discursive components. In conclusion, the empirical relevance of the proposed framework is substantiated by applying it to a specific case study of tertiary classroom discourse.
\end{abstract}

Keywords: English as a lingua franca, English-medium tertiary education, linguistic repertoire, community of practice, institutionalised talk.

\section{Introduction}

In the European context, university education in a language other than the national or majority language was, until recently, a rare practice that was mostly reserved for study programmes focusing on that specific language. With the impact of globalisation on tertiary education and the so-called Bologna process, ${ }^{1}$ this situation has changed fundamentally. Most universities have taken on an internationalisation agenda (Graddol 2006:74), one aspect of which is the increasing adoption of English as medium of master's and lately also bachelor's programmes in mainland Europe, if not exclusively, then at least for parts of their classes (e.g. Nastansky 2004; Wächter and Maiworm 2008; Wilkinson and Zegers 2007).

As can be expected, these changes have attracted considerable interest, also within applied linguistics as recent publications testify (e.g. Dafouz and Núñez 2009; Fortanet-Goméz and Räisänen 2008; Wilkinson and Zegers 2007). During the same period, English as a lingua franca (ELF) has been identified as an important area of research (e.g. Jenkins 2007; Mauranen and Ranta 2009; Seidlhofer 2004). In contrast to the equally thriving, largely macro-sociolinguistic research undertakings into English as an international language and its diverse, often debatable consequences for multilingual speakers and societies (e.g. Pennycook 2007; Phillipson 2003), research into ELF tends to focus on the micro-level of English as means of communication amongst multilingual social actors, thus foregrounding the discursive dynamics of specific communicational settings. So far, the two research 
undertakings into English-medium education and ELF have developed more or less independently from each other. In view of the extant overlap between these research agendas, this paper argues that the present situation of related research undertakings being conducted side by side in such a seemingly indifferent manner, misses out on the considerable potential of cross-fertilisation of insights and findings.

The need to merge these investigative frames becomes especially relevant in light of the fact that the internationalisation endeavours of many European universities entail that their teachers and learners have to rely on English as their only shared means of communication, even though they usually have diverse and multilingual repertoires. Given these realities, this paper addresses the research question of how classroom practices can be conceptualised when relying on English as the participants' lingua franca. This will be done by, firstly, presenting the ELF perspective as helpful and insightful for researching English-medium tertiary education and, secondly, suggesting a novel dynamic conceptualisation of ELF as tertiary classroom language.

\section{English as a lingua franca}

Since the 1990s, research concerned with the English language has been enriched by a new research focus: English as a lingua franca (ELF). While definitions of ELF differ, researchers largely agree on the basic understanding that it:

... refer[s] to the use of English amongst multilingual interlocutors whose common language is English and who [usually] communicate in a country or area in which English is not used in daily life.

(Smit 2005:67)

Although English had been functioning as a lingua franca for a long time already, the sociopolitical and economic developments of the late twentieth century made this function increasingly relevant. In the current era of globalisation, the claim has been made repeatedly that English is used as lingua franca more often than as means of communication amongst L1 speakers (e.g. Crystal 2003; Graddol 2006).

Given these realities, it was only a question of time before applied linguistic researchers would turn to ELF in an attempt to find out more about the ins and outs of English in this function. Motivated by considerations for the English language learning enterprise, the first publications focused on issues related to language planning, thus remaining on the macrolevel (Hüllen 1982; Smith 1984). These thought-provoking ideas found support in the first micro-level studies of the 1990s (e.g. Firth 1990; House 1996; Meierkord 1996), but it was with the beginning of the new millennium that ELF research really took off. To be mentioned in this context are Jenkin's (2000) first book-length study on ELF pronunciation, Seidlhofer's (2001) programmatic "conceptual gap" paper and the start of compiling the first corpora of spoken ELF (e.g. Mauranen 2003). The last ten years have then not only seen the finalisation of three corpora - ELFA, VOICE and $\mathrm{ACE}^{2}$ - but also an impressive array of empirical studies into ELF, undertaken in a variety of mainly European and Asian countries (see, for example, papers published in English Today 2008; Intercultural Pragmatics 2009; International Journal of the Sociology of Language 2006; Nordic Journal of English Studies 2006; and Mauranen and Ranta 2009). With regard to domains of language use, ELF research has been interested in a broad range, including casual conversation (e.g. Kordon 2006; Pölzl and Seidlhofer 2006), business encounters (e.g. Ehrenreich 2009; Nickersson 2005), and the 
domain focused on in this paper, namely, tertiary education (e.g. Björkman 2009; Mauranen 2006; Smit 2010).

\section{ELF and higher education}

Given that research into English-medium university-level education has been undertaken outside mainland Europe for about fifty years at least and has resulted in an impressive body of findings and insights, ${ }^{3}$ critical voices might doubt the relevance of yet another take on the matter. In this light, it is important to specify what the added value of the ELF paradigm might be for analysing English-medium higher education, especially in Europe. The first reason for favouring this new approach can be found in the geographical focus: Englishmedium education is a novelty for mainland Europe. This status as newcomer already marks English-medium education as socio-politically different from countries and areas where it has been a widespread practice for a long time. While the use of English (or other additional languages) as medium at all educational levels is supported by official EU papers (e.g. European Commission 1995; 2008) and national policies in most European countries (Eurydice 2006), ${ }^{4}$ it stands in stark contrast to the still stronger practice of education undertaken in the respective national or majority language. The vast majority of Englishmedium education research, however, has been undertaken in "Inner Circle" settings - i.e., with English as national or majority language - or in "Outer Circle" countries where English has functioned as main educational language for socio-political and historical reasons. ${ }^{5}$ In view of such fundamentally different socio-political contingencies, particular care needs to be taken when comparing research findings across settings.

While politically hailed as a welcome consequence of globalisation and internationalisation, the rapidly increasing use of English as medium of European tertiary institutions has stirred emotions - specifically within the field of applied linguistics - and triggered publications concerned with potential implications on various levels. Ehlich (2000) for instance, argues that, while the reduction of academic languages to mainly English might have the practical value of a wider expert readership, it impoverishes the diversity of academic languages and also leads to a loss in scientific and scholarly transparency within non-English speaking communities (cf. also Ammon and McConnell 2002). Furthermore, warnings can be heard more regularly in smaller European countries that the increased use of English as educational language might result in the respective national languages losing out on this function. This, in turn, could have repercussions in terms of the status and prestige attached to these languages within their speech communities. Fears such as these have been reflected in recent Scandinavian and Dutch publications, which have added a decidedly more careful and warning tone on the use of English as medium of higher education as regards various concerns, such as official language planning initiatives (Shaw et al. 2008), actual teaching and learning practices (Dafouz and Núñez 2010) as well as people's ideas and beliefs about participating in English-medium tertiary education (Hellekjær 2010).

Implicit in most of these publications, but explicit in only a handful, is the research issue at the heart of this paper: the conceptualisation of what English is at stake in such tertiary educational settings. Seeing that English is an additional language to most of the participants in these settings (that is, teachers and learners), the default concept of English as the language of monolingual English speakers will surely not work. However, since the long-standing tradition of categorising language according to the "monolingual habitus" (Gogolin 2008) has also left deep marks in the field of applied linguistics, the usual conceptualisation of the 
English analysed tends to be based on the distinction between "native" vs. "non-native" English and its use as a second or foreign language. As explicated in a series of critical papers on the explicitly monolingual, dangerously generalising assumptions of native language competence, this categorisation falls short on various counts: firstly, multilingualism is too widely spread for the monolingual speaker of English to be installed as sole point of reference (Rampton 1990). Secondly, in our globalised world, the distinction between second and foreign language speakers leads to a proliferation of further distinctions without neccesarily providing deeper insight (cf. Gnutzmann and Intemann 2008). Thirdly, the labelling of "L2" and "L3" selects the criterion of acquisitional sequence as decisive one, thereby arguably implying a linear relationship between personal language learning history, language proficiency level achieved and communicative functional breadth (Smit 2010:52). More importantly, such labels foreground the L1 or native speaker to such an extent that (as pointed out by Firth and Wagner 1997; 2007) research in this tradition has been heavily influenced, not to say biased, by a strongly comparative approach. According to this approach Englishmedium classroom discourse is analysed and interpreted in contrast to (assumed) native speaker discourse, with inevitable differences between the two readily interpreted as formal and functional language deficiencies.

This is not to say that pedagogical questions of accuracy with regard to specific language norms are irrelevant or that individual students might not want to improve on their English. On the contrary, language learning remains an important issue for many individuals. Nevertheless, it is important to keep in mind why English is used as medium of teaching and learning in mainland European tertiary institutions: it is the communicational means by which target groups of international students can be attracted, and by means of which they will be able to engage in educational discourse. English is thus chosen to make tertiary education possible, not to help students improve on their English. In other words, English functions as the only language the participants in such educational practices have in common - as their lingua franca. Investigations should acknowledge this important motive and build on the recent research literature on ELF, precisely because it focuses explicitly on English in this very function of allowing social actors to participate in classroom discourse.

Interestingly, such research-based considerations find support in insider evaluations participants share in such educational settings. The following four quotations are taken from interviews with participants of an English-medium international hotel management course (Smit 2010:chapter 4.3) and illustrates some of the perceptions teachers and students hold of their educational setting and the role that English plays in it:

(1) Interview with RER (Cooking teacher)

Ich unterricht eigentlich recht gern in englischer Sprache [.] ja wei- weil ma des wieder [.] ä so ein bisschen internationalen Weitblick internationalen Flair und und gibt also für mich is des ä an sich was sehr sehr Positives.

I actually like teaching in English (.) because that's how you get again a bit of an international approach, international flair, which is definitely something very, very positive for me.

(2) Interview with Cana (a Greek/German student)

Er [studying in English] is interesting. I think it makes erm things much easier later on. 
(3) Interview with Anns (an Indian student)

They [the students] do get on in class, but yes there are differences, some people are it is hard for them to understand because the way they have learnt English, is different. I mean even if you take the [Koreans] they have an accent [...] when they speak sometimes yes the others don't understand. But we yes we try to communicate with each other without fight and stuff so we understand each other well.

(4) Interview with Alac (a French/Venezuelan student)

Yeah [...] some teachers have better vocabularies than others I guess, [...but] you don't really need a high level of English 'cause that's not really the point I think. I mean as long as they get it across what they want to- what is important for this subject, if they don't have a fluent perfect English doesn't make a difference.

As the above statements show, these students and teachers view English as the one language they all share and that allows them access to international hospitality education and settings. Furthermore, the participants indicate that, since the main language used for communication (English) is an additional language for everyone, the focus should be on mutual support and understanding for the diversity in linguistic and cultural backgrounds, instead of on expectations of exonormative correctness, i.e. adherence to established language norms. In other words, the insider views underline that English is first and foremost the participants' lingua franca. ${ }^{6}$

\section{A conceptual frame}

Given the etic and emic support for approaching English in (mainland European) multilingual tertiary education from a lingua franca perspective, the next step is to aim for a conceptual frame of ELF in the tertiary classroom that allows for the complexity and diversity of educational differences and dynamics. The conceptual frame argued for in this article incorporates a variety of arguably decisive factors that can be grouped into four resources which jointly nurture ELF as classroom language. These resources are represented visually in figure 1 below (adapted from figure 2.1 in Smit 2010:66). Although they are visualised as separate sectors in figure 1, it should be noted that the resources work neither individually nor independently from each other, but "nurture" or construct jointly and flexibly the specific realities and dynamics of ELF as classroom language. 


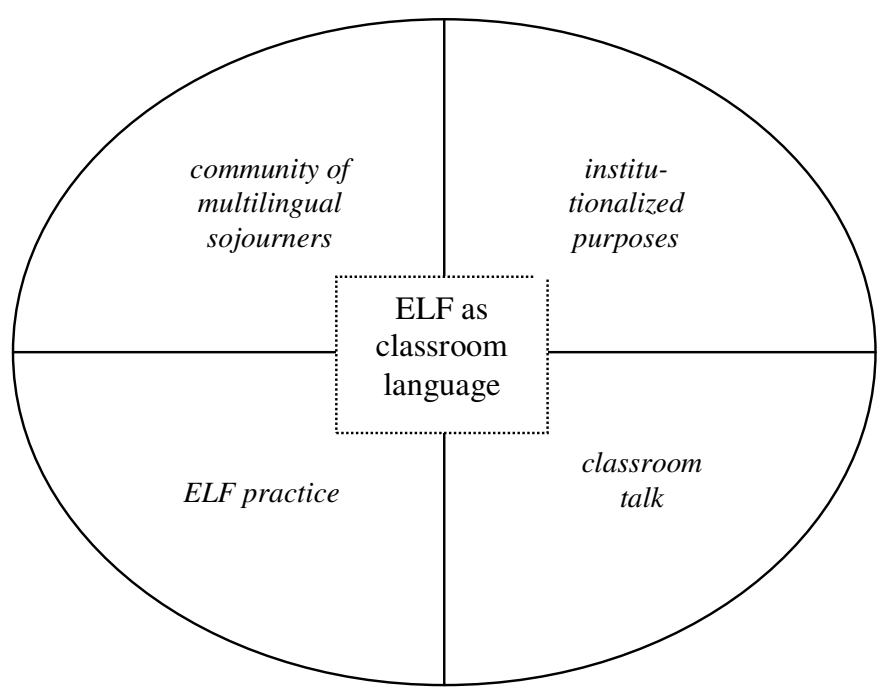

Figure 1. A conceptual frame for ELF as classroom language

As the geometrical shapes in figure 1 above illustrate, the four complex resources are considered as equally relevant to the conceptual frame and do not stand in any special order of preference. For the sake of convenience, the following description will deal with one component at a time, starting with the top left-hand sector of the ellipsis and continuing clockwise. The resource named "community of multilingual sojourners" focuses on the participants; i.e. the teachers and, more importantly, the students concerned. Given that classbased educational programmes require students to attend classes for a certain period of time, international students are by definition individually mobile and ready to act as "sojourners" or "temporary travellers in different cultures" (Bochner 2003:chapter 8, unit 7). The role of sojourner also has important implications as regards the participants' linguistic repertoires, that is, "the total range of codes available to the [multi]lingual speaker" (Banda 2009:6). With the exception of sojourning in cultures that rely on the same language code as that of the individual temporary traveller, international education usually presupposes bi- or multilingual repertoires and the willingness of the students to develop their repertoires further, such as when engaging in education in a language not previously used by the students for educational purposes. Additionally, the "language-scape" - i.e. "the range of languages operating in [the wider] community" (Wajnryb 2005:par. 7) where the educational programme is situated - will be of relevance as the sojourners need to tackle the challenges of everyday life as well. When going shopping, visiting a doctor or taking part in free-time activities, the language(s) of the environment will play a substantial role in the lives of the temporary residents.

As regards the educational undertaking itself, the social actors involved "negotiate [...] and learn [...] practices that contribute to the satisfaction of [learning as] common goal" (Meyerhoff 2002:530). In other words, they engage in a "community of practice" (Wenger 1998). As defined succinctly by Eckert (2000:35), communities of practice are "[u]nited by [some] common enterprise [and ...] develop and share ways of doing things, ways of talking, beliefs, values - in short, practices - as a function of their joint engagement in activity". Learning is surely such a "common enterprise" which, when seen from a social constructivist understanding (e.g. Vygotsky 1978), is also a social undertaking requiring "joint engagement". Furthermore, social learning is intrinsically discursive, requiring and constructing shared repertoires (e.g. Corder and Meyerhoff 2007). Interestingly, this concept does not only elucidate formal learning processes, but also ELF practices. ELF users "move[] in and out of a variety of contexts, which are likely to have quite different forms of 
participation [... and lead to] the construction of event-specific, interactional styles and frameworks" (House 2003:572). In other words, English used as a lingua franca functions as shared repertoire within groups of social actors who are mutually engaged in a joint enterprise. Overall then, the social actors engaged in ELF and tertiary learning practices form a community of multilingual sojourners for the duration of their particular educational programme.

The second resource presented in figure 1, namely, "institutionalized purposes", focuses on the joint enterprise of tertiary education in ELF. Although the specifics of such enterprises clearly depend on the type of education pursued, underlying them all must be the institutionalised purposes (cf. Drew and Heritage 1992:22) or "business of schooling" (Christie 2002:2), at the core of which we find learning. Following the sociocultural understanding sketched above, learning is intricately linked to classroom discourse. Marton, Runesson and Tsui (2004:4) proposed a definition of learning as "the acquired knowledge of something", with the "something" being conceived of as a capability which combines acting (for instance, remembering or interpreting) with "the thing or subject on which these acts are carried out". As teaching does not neccesarily coincide with learning, what is centrally relevant to the business of schooling is the space of learning that "is constituted by linguistic means in the interaction between teacher and students" (Marton, Runesson and Tsui 2004:24). In other words, what can be learnt in a specific situation is seen as contingent on classroom discourse. When this discourse relies centrally on English used as a lingua franca, the conclusion seems to be that ELF can fulfil the institutionalised purposes of tertiary education. At the same time, it must not be forgotten that we are concerned with multilingual social actors who presumably draw on their diverse multilingual repertoires when engaged in the cognitively challenging processes that form part of formal learning. It seems justified, therefore, to refrain from referring to English as "language of learning" and, instead, to stress its role as medium of instruction and classroom talk. Stated differently, English is the classroom language (cf. Smit 2010:80).

The third resource concerns the specific nature of language use in formal educational settings. As typical of all institutionalised discourse, "classroom talk" reveals characteristic features, patterns and dynamics concerning, amongst others, topic development, turn-taking, discourse functions or participatory roles (for recent overviews see Dalton-Puffer 2007:18; Smit 2010: 21-31). Probably the best known example with which to illustrate such specificities of classroom talk is the IRF exchange pattern, consisting of (teacher) Initiation - (student) Response - (teacher) Feedback. This tripartite sequence has attracted research interest since Sinclair and Coulthard's (1975) and Mehan's (1985) seminal investigations, and been analysed in form, function and pedagogical value since then (for a more recent account cf. Nikula 2007). The IRF pattern owes its prominence largely to the fact that it occurs frequently in classroom talk. However, the fact that it is perceived as institutionally specific and not easily comparable to "normal" two-part structures found in non-educational settings, has added to the prominence and negative connotation often associated with this particular exchange pattern. Such institutionalised contingencies of discourse hold an important lesson for investigating ELF as classroom language: findings from one institutionalised setting are relevant to that specific institution, and not automatically valid for others. When viewed in a more positive light, analyses of ELF as classroom language have the well-established literature on classroom talk as useful body of reference. 
The fourth resource, namely, "ELF practice", elaborates on the concept of English as a lingua franca with the aim to integrate it explicitly and centrally into the shared repertoire coconstructed by the community members (for a detailed discussion cf. Smit 2010:59-68). By definition, the function of ELF is to allow for interaction, which in turn is a social practice by which the community members construct meaning and, at the same time, "create, maintain and/or modify the[ir] collective history" (Hall 1993:146). In other words, interaction is relevant to the here-and-now of meaning-making as well as to long-term community developments. Given that lingua franca interactions have to rely on relatively little shared background amongst the participants - it wouldn't be their lingua franca otherwise communicating in the sense of making meaning in the specific interactional situation is usually at the forefront of the participants' concern. It is therefore understandable that COMMUNICATING in a fully situated way must be seen as central characteristics of ELF (cf. James 2006; 2007). At the same time, the long-term relevance of interaction applies to ELF as well, since except for rare once-off encounters, most ELF interactions stand in a sequence of discursive events constructing communities of practice (as discussed earlier in this paragraph). This long-term perspective implies that ELF interactions do more than fulfil momentary transactional needs. By constructing shared histories, ELF interactions are also instrumental for developing community-internal practices that are relevant beyond the momentary interactional needs. Once such practices have been identified as shared in the respective community, ELF can also draw on semi-situated language use. Such ESTABLISHED PRACTICES thus form a second dimension that, in addition to COMMUNICATING, characterises ELF interactions. The third and final dimension foregrounds the fact that ELF interlocutors bring their own linguistic backgrounds and histories - i.e. their non-situated linguistic repertoires - to each encounter. As multilingual speakers who are using English, all of them must draw to some extent on their English-related repertoires. Depending on the community constellation and the language-scape of the setting, however, other aspects of those repertoires will also become relevant, thus making INDIVIDUAL REPERTOIRE the third dimension. In summary, ELF practice relies on the dynamic interplay of the following three dimensions: (1) COMMUNICATING, (2) ESTABLISHED PRACTICE and (3) INDIVIDUAL REPERTOIRE. While the first is central to all ELF interactions, the other two gain or lose relevance depending on interactional purposes and constellations of participants.

The following brief description by Smit (2010:79) of how this three-dimensional conceptualisation applies to the ELF classroom is intended to highlight the proposed framework's conceptual and analytical strength:

Classroom discourse [...] unfolds by communicating in ELF in a highly situated way so that the small group of participants can make communication work. In the joint attempt to reach the educational goals related to the subject in question the [...] ELF practice also draws on the dimension established practice, viz. the relevant disciplinary ESP discourse, conventions and genres. Due to the typical role relations of teacher and students as predefined by the "setting" of formal education, it can be expected that it will usually be the teacher who initially enriches the [...] practice [...] and that, with time, parts of this established practice will be integrated into the classroom ELF practice. As regards the dimension individual repertoire [...] the kinds of English the members of the community of practice bring with them [are relevant], reflecting their personal English language learning and using histories. 
Overall, the frame argued for here offers an integrated conceptualisation of the resources that construct "ELF as classroom language". Each sector bundles the criteria that relate to one of the fundamental questions of social practices more generally: who is involved, why is what taking place, and how it is constructed. In their interplay, these resources allow for a comprehensive, but also flexible analysis of the dynamics and complexities involved in ELF as classroom language.

\section{In conclusion: Illustrating the conceptual frame}

By way of conclusion, this final section will illustrate how the frame accounts for the complexities of ELF as classroom language by applying it to one such educational programme: the HMP (Hotel Management programme) investigated in detail in Smit (2010). Since the study as such is a discourse-pragmatic ethnography, in other words, "a qualitative applied linguistic investigation that combines discourse analytical and pragmatic approaches with (educational) ethnography and aims at a principled analysis and informed interpretation of the classroom interaction" (Smit 2010:87), it offers a detailed, longitudinal and dynamic analysis of classroom discourse in ELF, paying specific attention to dynamic developments induced by time, discourse topics and different participant constellations. While a twodimensional graph obviously cannot do full justice to multidimensional dynamics, figure 2 below presents a concise delimitation of the four resources in their case-specific realisations: 


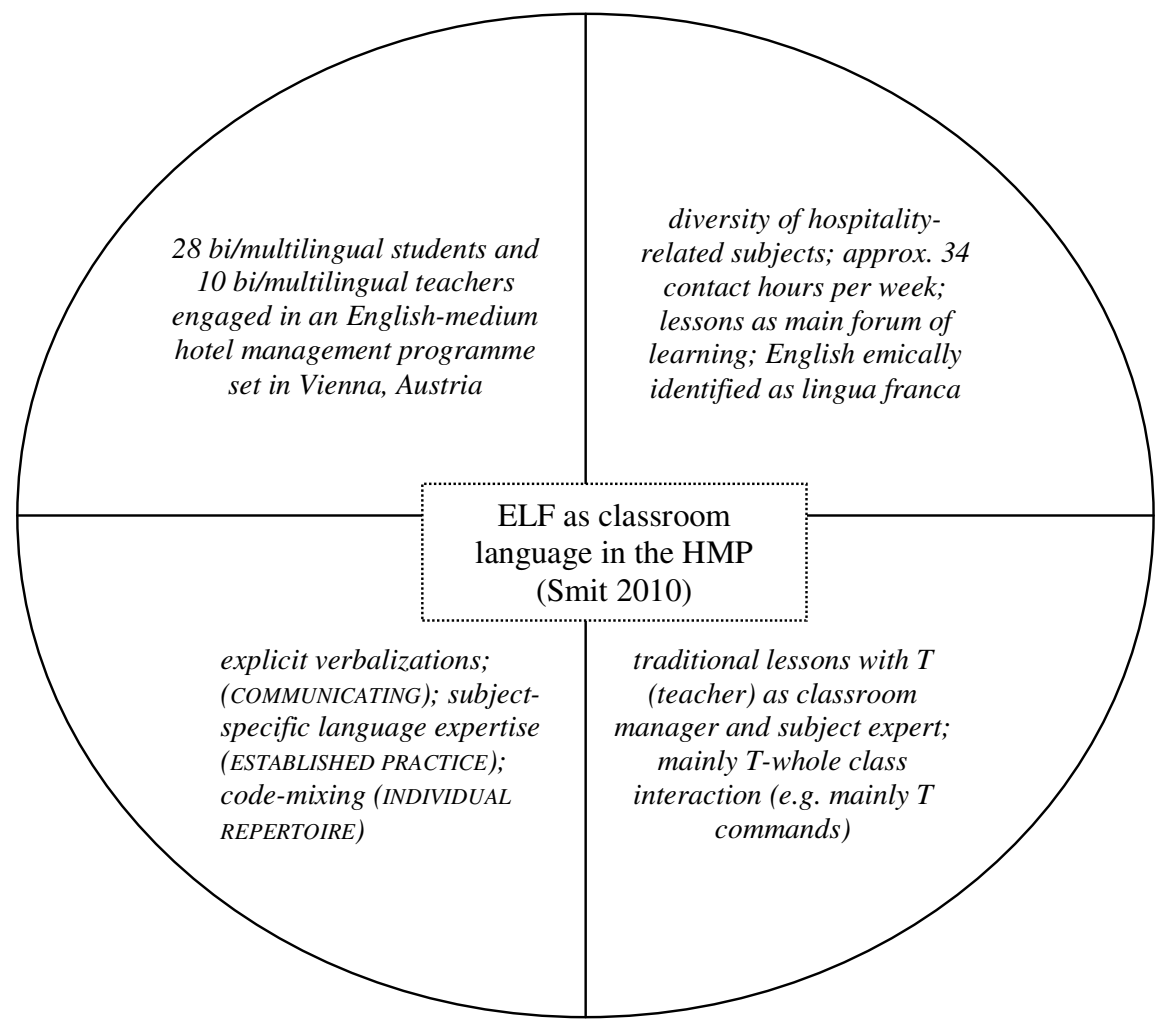

Figure 2. A case of ELF as classroom language

As summarised in the four sectors in figure 2, ELF as classroom language in the specific case of the HMP relies on the four resources (cf. figure 1) in the following ways:

(i) In line with the description of the first resource, namely, "community of multilingual sojourners", this sector describes the social actors. That is, (i) the 28 multilingual students who attended the four-semester post-secondary hotel management programme (HMP) in Vienna, (ii) the largely bilingual, mainly Austrian teachers of diverse professional backgrounds who lectured on topics of their professional specialisation, and (iii) the HMP itself that is set in German-speaking Vienna, but conducted in English specifically because it caters for international students aiming to get specialised knowledge for an international line of business, namely, tourism. The students' and teachers' views on the function that English fulfilled in their classes reflected this design strikingly: all of them identified English as language of the business as well as the only language shared by the community (see (1)-(4) in section $3)$.

(ii) Apart from the generally relevant joint enterprise of tertiary education, the "institutionalised purposes" of the HMP relate directly to the many diverse subjects offered as part of this programme, such as Hotel Management, Accounting, Human Relations or Communication and Presentation. Furthermore, the joint enterprise that community members strive for is influenced by the many contact hours: students spent 32-36 hours in class every week, which left little time for self-study. As teachers structured their teaching accordingly, the lessons themselves functioned as the main forum of potential learning. This in turn means that, to a considerable degree, classroom discourse created the central "space for learning". The centrality of English in this learning process was also identified by many participants. 
(iii) The specificities of the HMP classes allow for a more detailed description of the parameters of "classroom talk": as the lessons were typically teacher-focused with the teacher acting as classroom manager as well as subject knowledge expert, it is fair to say that the HMP offered mainly traditional lessons (Christie 2002). Consequently, teacher lecturing and teacher-whole class exchanges were the main interactional forms, with pair and group work appearing now and again. Such lesson structuring fit well with some of the interactional findings, such as the fact that almost all control acts were performed by the teachers. Control acts are understood here as commands for non-verbal actions (Ervin-Tripp, Guo and Lampert 1990:308) such as "open the door", which were analysed in a subset of the collected classroom data (cf. also Smit 2009).

(iv) The description of the HMP's "ELF practice" relies on a variety of discoursepragmatic analyses of classroom talk, which offered complex findings on how the participants managed to construct meaning, direct classroom talk and explain discourse topics. Additionally, the longitudinal methodology applied led to timedependent results that allowed for insights into the dynamics of ELF practices in the HMP. The following sketch is intended to illustrate the link between the findings and the three dimensions of ELF practice: classroom talk has been found to rely increasingly on the principle of explicitness, which can be paraphrased as "say what you mean and mean what you say". This principle clearly reflects the demands on meaning-making in the here and now, referred to above as the dimension of COMMUNICATING. At the same time, the analyses showed that teachers (were expected to) function(ed) as experts not only of their subjects, but also of the respective terminology. In this regard, then, classroom talk reflected the dimension of ESTABLISHED PRACTICE. Finally, the dimension of INDIVIDUAL REPERTOIRE was acted on as well, as, for instance, when individual German words started to be used in classroom talk during the second year of studies, thus indicating that these words, originally part of some individual repertoires and of the language-scape had made it into the community's shared repertoire.

In sum, the conceptual frame and its four resources introduced in this paper allow for a concise characterisation of ELF as classroom language in a specific educational case of "a temporary and developing community of practice, whose members are individually mobile bior multilingual English speaking [...] students [and teachers]" (Smit 2010:81). In pursuing their subject-specific educational goals, the community members' overarching communicative aim is to attain shared understanding on the respective objects of learning, thus using their individual repertoires to construct highly situated discursive practices, while also drawing on semi-situated established practices. Such discursive practices remain flexible, contextually dependent and dynamic, which is what the framework suggested here allows for in that it foregrounds the four resources and their constant interplay in English functioning as a lingua franca in tertiary classrooms.

In this light, there is further potential in the usability of the conceptual frame: as regards a longitudinal study such as the one reported here, the frame could be applied to the case study repeatedly, thus providing snapshots of ELF functioning as classroom language at various points in time. When re-assembled, the sequence of ELF-as-classroom-language frames could then offer insights into long-term changes and developments. Alternatively and as an offer to other researchers "out there", the frame might function as analytical template across studies 
which would make detailed and reconstructable comparisons between diverse investigations more transparent and likely. Moreover, given the novelty of the ELF approach to tertiary classroom research, further and comparative research is sorely needed.

\section{Notes}

1. The 'Bologna process' aims at creating the European Higher Education Area. By signing the Bologna Declaration in 1999, all European nations committed themselves to stream-lining academic education and making it more compatible across national systems, with the aim to allow for increased mobility of students and staff (for more information cf. http://www.ehea.info/).

2. ELFA (English as a Lingua Franca in Academic Settings) is localised in Tampere and Helsinki, Finland; VOICE (Vienna Oxford International Corpus of English) is located in Vienna, Austria and ACE (Asian Corpus of English) in HongKong, China. Of these corpora, only VOICE is publicly accessible.

3. For more information on research into English-medium university education see also Banda (2009), Ferguson (2006), Lin and Martin (2005) and Tsui and Tollefson (2007).

4. Eurydice is a network of educational agencies in 31 European countries with a coordinating unit in Brussels. The mission of Eurydice is "[t]o provide those responsible for education systems and policies in Europe with European-level analyses and information which will assist them in their decision making." (http://eacea.ec.europa.eu/education/eurydice/about_eurydice_en.php).

5. For the original accounts of the "Three Circle Model" of World Englishes see Kachru (1982); for more recent critical evaluations refer to Gnutzmann and Intemann (2008) or Yano (2009).

6. See Ehrenreich (2009) for similar evaluations of participants in ELF discourses in business settings.

\section{References}

ACE (Asian Corpus of English). Available online at http://www.ied.edu.hk/rcleams/view.php ?secid=227. Accessed on 21 September 2010.

Ammon, U. and G. McConnell. 2002. English as an academic language in Europe. A survey of its use in teaching. Frankfurt a. M.: Lang.

Banda, F. 2009. Critical perspectives on language planning and policy in Africa: Accounting for the notion of multilingualism. SPIL PLUS. Special Issue: Multilingualism and Language Policies in Africa 38: 1-11.

Björkman, B. 2009. From code to discourse in spoken ELF. In A. Mauranen, and E. Ranta (eds.). English as a lingua franca: Studies and findings. Newcastle upon Tyne: Cambridge Scholars. pp.225-251.

Bochner, S. 2003. Culture shock due to contact with unfamiliar cultures. In W.J. Lonner, D.L. Dinnel, S.A. Hayes and D.N. Sattler (eds.). Online readings in psychology and culture. Unit 8, Chapter 7. Center for Cross-Cultural Research, Western Washington University, Bellingham, Washington USA. Available online at http://www.wwu.edu/ culture.

Christie, F. 2002. Classroom discourse analysis. London: Continuum.

Corder, S. and M. Meyerhoff. 2007. Communities of practice in the analysis of intercultural communication. In H. Kothoff and H. Spencer-Oatey (eds.). Handbook of intercultural communication, HAL 7. Berlin: Mouton de Gruyter. pp. 441-461.

Crystal, D. 2003. English as a global language. Second edition. Cambridge: Cambridge University Press. 
Dafouz, E. and B. Núñez. 2009. CLIL in higher education: Devising a new learning landscape. In E. Dafouz and M.C. Guerrini (eds.). CLIL across educational levels. Madrid: Richmond. pp. 101-110.

Dafouz, E. and B. Núñez. 2010. Metadiscursive devices in university lectures: a contrastive analysis of L1 and L2 teacher performance. In C. Dalton-Puffer, T. Nikula and U. Smit (eds.). Language use and language learning in CLIL classrooms. Amsterdam: Benjamins. pp. 213-232.

Dalton-Puffer, C. 2007. Discourse in content and language integrated (CLIL) classrooms. Amsterdam: Benjamins.

Drew, P. and J. Heritage. 1992. Analyzing talk at work: An introduction. In P. Drew and J. Heritage (eds.). Talk at work: Interaction in institutional settings. Cambridge: Cambridge University Press. pp. 3-65.

Eckert, P. 2000. Linguistic variation as social practice. Malden, Mass: Blackwell.

Ehlich, K. 2000. Deutsch als Wissenschaftssprache für das 21. Jahrhundert. German as a Foreign Language (GFL). 1/2000: 47-63.

Ehrenreich, S. 2009. English as a lingua franca in multinational corporations. An exploration of business communities of practice. In A. Mauranen and E. Ranta (eds.) English as a lingua franca: Studies and findings. Newcastle upon Tyne: Cambridge Scholars. pp. 126-151.

ELFA (English as a lingua franca in academic settings). Available online at http://www.uta.fi/laitokset/kielet/engf/research/elfa. Accessed 21 September 2010.

English Today. 2008. Special issue on English as a lingua franca. 24(2).

Ervin-Tripp, S., J. Guo and M. Lampert. 1990. Politeness and persuasion in children's control acts. Journal of Pragmatics 14: 307-331.

European Commission. 1995. White paper on education and learning: Teaching and learning. Towards the learning society.Available online at http://europa.eu/documents/ comm/white_papers/pdf/com95_590_en.pdf.

European Commission. 2008. Languages and Europe: Language learning. Available online at http://europa.eu/languages/en/chapter/14.

Eurydice. 2006. Content and Language Integrated Learning (CLIL) at school in Europe. Directorate-General for Education and Culture of the European Commission. Available online at http://eacea.ec.europa.eu/ressources/eurydice/pdf/0_integral/071EN.pdf.

Ferguson, G. 2006. Language planning and education. Edinburgh: Edinburgh University Press.

Firth, A. 1990. 'Lingua franca' negotiations: Towards an interactional approach. World Englishes 9(3): 269-280.

Firth, A. and J. Wagner. 1997. On discourse, communication, and (some) fundamental concepts in SLA research. The Modern Language Journal 81(3): 285-300.

Firth, A. and J. Wagner. 2007. Second/ foreign language learning as a social accomplishment: Elaborations on a reconceptualised SLA. Modern Language Journal 91: 800-819.

Fortanet-Gómez, I. and C.A. Räisänen (eds.). 2008. ESP in European higher education. Integrating language and content. Amsterdam: John Benjamins.

Gnutzmann, C. and F. Intemann. 2008. Introduction: The globalisation of English. Language, politics and the English language classroom. In C. Gnutzmann and F. Intemann (eds.). The globalisation of English. Language, politics and the English language classroom. Tübingen: Narr. pp. 9-24.

Gogolin, I. 2008. Der monolinguale Habitus der multilingualen Schule. Münster: Waxmann.

Graddol, D. 2006. English next. Why global English might mean the end of 'English as a Foreign Language'. British Council. 
Hall, J.K. 1993. The role of oral practices in the accomplishment of our everyday lives: the sociocultural dimension of interaction with implications for the learning of another language. Applied Linguistics 14(3): 145-166.

Hellekjær, G.O. 2010. Language matters: assessing lecture comprehension in Norwegian English-medium higher education. In C. Dalton-Puffer, T. Nikula and U. Smit (eds.). Language use and language learning in CLIL classrooms. Amsterdam: Benjamins. pp. 233-258.

House, J. 1996. Developing pragmatic fluency in English as a foreign language. Routines and metapragmatic awareness. Studies in Second Language Acquisition 18: 225-252.

House, J. 2003. English as a lingua franca: A threat to multilingualism? Journal of Sociolinguistics 7(4): 556-578.

Hüllen, W. 1982. Teaching a foreign language as 'lingua franca'. Grazer Linguistische Studien 16: $83-88$.

Intercultural Pragmatics. 2009. Special issue on The pragmatics of English as a lingua franca. 6(2).

International Journal of the Sociology of Language. 2006. Special issue on lingua franca language use. 177.

James, A. 2006. Lingua Franca English as Chimera: sociocultural and sociolinguistic perspectives. In W. Delanoy and L. Volkmann (eds.). Cultural studies in the ELF classroom. Heidelberg: Universitätsverlag Winter. pp. 221-232.

James, A. 2007. Exploring the generic nature of international English. In U. Mozetič and S. Komar (eds.). English language overseas. Perspectives and enquiries (ELOPE) III: 7584. Available online at http://www.sdas.edus.si/index_files/elope.htm.

Jenkins, J. 2007. English as a lingua franca: Attitude and identity. Oxford: Oxford University Press.

Kachru, B.B. (ed.). 1982. The other tongue: English across cultures. Urbana, Illinois: University of Illinois Press.

Kordon, K. 2006. "You are very good" - establishing rapport in English as a lingua franca: the case of agreement tokens. Vienna English Working Papers (VIEWS) 15(2): 58-83. Available online at http://www.univie.ac.at/Anglistik/ang_new/online_papers/views. html.

Lin, A.M.Y and P.W. Martin (eds.). 2005. Decolonisation, globalisation. Language-ineducation policy and practice. Clevedon: Multilingual Matters

Marton, F., U. Runesson and A.B.M. Tsui. 2004. The space of learning. In F. Marton and A.B.M. Tsui (eds.). Classroom discourse and the space of learning. Mahwah, NJ: Erlbaum. pp. 3-40.

Mauranen, A. 2003. The corpus of English as lingua franca in academic settings. TESOL Quarterly 37(2): 513-527.

Mauranen, A. 2006. Signalling and preventing misunderstanding in English as lingua franca communication. International Journal of the Sociology of Language 177: 123-150.

Mauranen, A. and E. Ranta (eds.). 2009. English as a lingua franca: Studies and findings. Newcastle upon Tyne: Cambridge Scholars.

Mehan, H. 1985. The structure of classroom discourse. In T. van Dijk (ed.). Handbook of discourse analysis. Vol. 3: Discourse and dialogue. London: Academic Press. pp. 119131.

Meierkord, C. 1996. Englisch als Medium der interkulturellen Kommunikation. Untersuchungen zum non-native- / non-native-speaker Diskurs. Frankfurt: Lang. 
Meyerhoff, M. 2002. Communities of practice. In J.K. Chambers, P. Trudgill and N. Schilling-Estes (eds.). The handbook of language variation and change. Malden, M.A.: Blackwell. pp. 521-548.

Nastansky, H-L. 2004. National strategy in the internationalisation of higher education: the German perspective. In R. Wilkinson (ed.). Integrating content and language. Meeting the challenge of a multilingual higher education. Maastricht: Universitaire Pers. pp. 49-54.

Nickersson, C. 2005. English as a Lingua Franca in International Business Contexts. English for Specific Purposes 24(4): 367-380.

Nikula, T. 2007. The IRF pattern and space for interaction: comparing CLIL and EFL classrooms. In C. Dalton-Puffer and U. Smit (eds.). Empirical perspective on Content and Language Integrated Learning (CLIL). Frankfurt: Lang. pp. 179-204.

Nordic Journal of English Studies. 2006. Special issue on English as a lingua franca. 5(2).

Pennycook, A. 2007. Global Englishes and transcultural flows. London: Routledge.

Phillipson. R. 2003. English-only Europe. Challenging language policy. London: Routledge.

Pölzl, U. and B. Seidlhofer. 2006. In and on their own terms: the "habitat factor" in English as a lingua franca interactions. International Journal of the Sociology of Language 177: 151-176.

Rampton, B. 1990. Displacing the 'native speaker': expertise, affiliation, and inheritance. ELT Journal 44(2): 97-101.

Seidlhofer, B. 2001. Closing a conceptual gap: the case for a description of English as a lingua franca. International Journal of Applied Linguistics 11(2): 133-158.

Seidlhofer, B. 2004. Research perspectives on teaching English as a lingua franca. Annual Review of Applied Linguistics 24: 209-239.

Shaw, P., C. Benson, S. Brunsberg, R. Druhs and D. Minugh. 2008. Preparing for international masters degrees at Stockholm University and the Royal Institute of Technology in Stockholm. In I. Fortanet-Gómez and C.A. Räisänen (eds.). ESP in European higher education. Integrating language and content. Amsterdam: John Benjamins. pp. 267-282.

Sinclair, J. and M. Coulthard. 1975. Towards an analysis of discourse. The English used by teachers and pupils. Oxford: Oxford University Press.

Smit, U. 2005. Multilingualism and English. The lingua franca concept in language description and language learning pedagogy. In R. Faistauer, C. Cali, I. Cullin and K. Chester (eds.). Mehrsprachigkeit und Kommunikation in der Diplomatie. Favorita Papers 4. Vienna: Diplomatic Academy. pp. 66-76.

Smit, U. 2009. Emic evaluations and interactive processes in a classroom community of practice. In A. Mauranen and E. Ranta (eds.). English as a lingua franca: Studies and findings. Newcastle upon Tyne: Cambridge Scholars Publishers. pp. 200-224.

Smit, U. 2010. English as a lingua franca in higher education. A longitudinal study of classroom discourse. Berlin: Mouton.

Smith, L.E. 1984. Teaching English as an international language. Studium Linguistik 15:5259.

Tsui, A.B.M. and J.W. Tollefson (eds.). 2007. Language policy, culture and identity in Asian contexts. Mahwah, NJ.: Lawrence Erlbaum.

VOICE (Vienna Oxford International Corpus of English). Available online at http://www.univie.ac.at/voice/. Accessed on 21 September 2010.

Vygotsky, L.S. 1978. Mind in society (edited by Michael Cole). Cambridge, Mass: Harvard University Press. 
Wächter, B. and F. Maiworm. 2008. English-taught programmes in European higher education. The picture in 2007. Bonn: Lemmens.

Wajnryb, R. 2005, April 23. More scope for scape. The Sydney Morning Herald. Available online at http://www.smh.com.au/news/Words/More-scope-for-scape/2005/04/21/111 4028473080.html.

Wenger, E. 1998. Communities of practice. Learning, meaning, and identity. Cambridge: Cambridge University Press.

Wilkinson, R. and V. Zegers (eds.). 2007. Researching content and language integration in higher education. Maastricht: Universitaire Pers.

Yano, Y. 2009. English as an international lingua franca: From societal to individual. World Englishes 28(2): 246-255. 